\title{
Metabolic engineering of Deinococcus radiodurans for pinene production from glycerol
}

\author{
Seyed Hossein Helalat ${ }^{1}$, Carsten Jers $^{2}$, Mandana Bebahani ${ }^{1 *} \mathbb{D}$, Hassan Mohabatkar ${ }^{1}$ and Ivan Mijakovic ${ }^{2,3}$
}

\begin{abstract}
Background: The objective of this work was to engineer Deinococcus radiodurans R1 as a microbial cell factory for the production of pinene, a monoterpene molecule prominently used for the production of fragrances, pharmaceutical products, and jet engine biofuels. Our objective was to produce pinene from glycerol, an abundant by-product of various industries.

Results: To enable pinene production in D. radiodurans, we expressed the pinene synthase from Abies grandis, the geranyl pyrophosphate (GPP) synthase from Escherichia coli, and overexpressed the native 1-deoxy-D-xylulose 5-phosphate synthase. Further, we disrupted the deinoxanthin pathway competing for the substrate GPP by either inactivating the gene dr0862, encoding phytoene synthase, or substituting the native GPP synthase with that of E. coli. These manipulations resulted in a D. radiodurans strain capable of producing $3.2 \pm 0.2 \mathrm{mg} / \mathrm{L}$ pinene in a minimal medium supplemented with glycerol, with a yield of $0.13 \pm 0.04 \mathrm{mg} / \mathrm{g}$ glycerol in shake flask cultures. Additionally, our results indicated a higher tolerance of $D$. radiodurans towards pinene as compared to $E$. coli.

Conclusions: In this study, we successfully engineered the extremophile bacterium $D$. radiodurans to produce pinene. This is the first study demonstrating the use of $D$. radiodurans as a cell factory for the production of terpenoid molecules. Besides, its high resistance to pinene makes $D$. radiodurans a suitable host for further engineering efforts to increase pinene titer as well as a candidate for the production of the other terpenoid molecules.
\end{abstract}

Keywords: Pinene, Biofuel, Deinococcus radiodurans R1, Metabolic engineering, Monoterpene, Glycerol

\section{Background}

In recent years, issues regarding sustainable development of the human society have come to the fore. Concerns regarding fossil fuels are on the rise, related to depletion of their reserves, and risks connected to their distribution and environmental impact $[1,2]$. The use of fossil fuels has been related to production of greenhouse gases and augmentation of metal particles, NOX, and SOX in the atmosphere [3]. Recent reports have indicated that about $87 \%$ of global $\mathrm{CO}_{2}$ emissions are caused by human activities. According to current predictions, the human population will exceed 9 billion by 2050 , which leads to

*Correspondence: ma.behbahani@ast.ui.ir

${ }^{1}$ Department of Biotechnology, Faculty of Biological Science and Technology, University of Isfahan, Isfahan, Iran

Full list of author information is available at the end of the article increased concerns about sustainable development [4]. These challenges have led to a substantial push to secure energy and chemicals from sustainable sources. In this respect, microbial cell factories are playing a major role. They are capable of converting low value by-products of agriculture or industries into high value chemicals or biofuels [5].

Glycerol is a by-product of various large-scale industrial processes, such as production of soap (saponification of triglycerides) and biodiesel (transesterification). Hence, it has been proposed as a cheap carbon source for fermentation [6]. Compared to glucose, glycerol is a more reduced carbon source, delivering more reducing equivalents per unit price [7]. Hence, this polyol compound is a convenient carbon source for producing valuable molecules using microbial cell factories. otherwise in a credit line to the material. If material is not included in the article's Creative Commons licence and your intended use is not permitted by statutory regulation or exceeds the permitted use, you will need to obtain permission directly from the copyright holder. To view a copy of this licence, visit http://creativecommons.org/licenses/by/4.0/. The Creative Commons Public Domain Dedication waiver (http://creativecommons.org/publicdomain/zero/1.0/) applies to the data made available in this article, unless otherwise stated in a credit line to the data. 
Ethanol is the most popular biofuel globally [8]. However, requests for fuels with a higher combustion power that can be applied directly in the existing engines have led to development of other compounds as advanced biofuels [9]. Butanol [10], butene and its oligomers [11], fatty acids, hydro-processed esters [12], bisabolene, farnesene [13], and pinene are examples of such advanced biofuels. Pinene stands out among these molecules as a compound that can produce a high energy level close to that of JP-10 fuel required for jet engines [14]. This monoterpene is produced in low amounts by certain plants, but pinene extraction from these plants is inefficient, tedious, and costly. In addition to its use as an advanced biofuel, pinene is widely used in the production of insecticides, fragrances, flavors, and pharmaceutical products [15].

The enzyme pinene synthase catalyzes the formation of either $\alpha$ - and/or $\beta$-pinene by cyclization of GPP. Pinene synthase is mostly found in plants, notably pine trees such as A. grandis, Pinus taeda, and Picea abies. Several pinene synthases have been characterized, with some producing both isomers of pinene ( $\alpha$ and $\beta$ ), and others only one isomer. Both $\alpha$ and $\beta$ isomers can be exploited in dimer form as a powerful biofuel $(\alpha$-pinene dimer: 146.900 BTU, $\beta$-pinene dimer: 146.500 BTU) $[14,16]$. Various pinene synthases have been exploited for pinene production in microorganisms. In a comparative study, the pinene synthase from $A$. grandis was shown to allow production of the highest amounts of both isomers in $E$. coli [16].

Recent advances in the field of metabolic engineering of microbial cell factories have opened a new venue for pinene production using cheap carbon sources. Most of the efforts to produce pinene in microbial cell factories have been focused on Escherichia coli. However, the pinene yields and titers in engineered $E$. coli strains are still below the threshold for industrial production. The highest pinene titer reported so far is $166.5 \mathrm{mg} / \mathrm{L}$ in shake flask cultures and $0.97 \mathrm{~g} / \mathrm{L}$ in fed-batch fermentation [15, 17]. According to previous studies, limitations in pinene production by $E$. coli might be associated with the toxicity of pinene and GPP (the main precursor of pinene), as well as limited availability of manganese as the main cofactor of pinene synthase [16]. Given the limitations of $E$. coli for pinene production, we decided to investigate Deinococcus radiodurans as a potential alternative in this regard.

Deinococcus radiodurans is known to be extremely tolerant to different sources of stress: ionizing radiation, reactive oxygen species, UV light, heavy metals, dryness, high salinity, and alcohols. Additionally, it is able to utilize various carbon sources (different sugars, glycerol, fats, and proteins) $[18,19]$, making it a promising candidate for various purposes such as bioremediation, decomposition of toxic compounds, and production of valuable molecules $[20,21]$. Considering that manganese is the main cofactor of most pinene synthases, including that of $A$. grandis, the presence of high levels of manganese in $D$. radiodurans $(0.2-4 \mathrm{mM})$ is another positive feature [22]. Most importantly, D. radiodurans harbors a robust non-mevalonate GPP production pathway [23] and can produce significant amounts of the pigment deinoxanthin for which GPP is a precursor [24]. These distinguishing features make $D$. radiodurans a promising platform for producing terpene compounds in different standard or harsh conditions and growing on various carbon sources. On the other hand, some challenges such as the lack of genetic engineering tools such as strong-induciable promoters and insufficient metabolic knowledge for this strain should be considered.

In this study, D. radiodurans a hyperextremophile bacterium, was successfully engineered to produce pinene in a minimal medium supplemented with glycerol. Our production strain expressed the pinene synthase from A. grandis, the GPP synthase from E. coli, and overexpressed the native 1-deoxy-D-xylulose 5-phosphate synthase (DXS) in a mutant of $d r 0862$ (encoding phytoene synthase). This strain was capable of producing $3.2 \pm 0.2 \mathrm{mg} / \mathrm{L}$ pinene in a minimal glycerol medium.

\section{Materials and methods}

\section{Bacterial strains and growth conditions}

For plasmid propagation, E. coli NM522 was grown in LB culture medium $(10 \mathrm{~g} / \mathrm{L}$ tryptone, $5 \mathrm{~g} / \mathrm{L} \mathrm{NaCl}$, and $5 \mathrm{~g} / \mathrm{L}$ yeast extract) at $37{ }^{\circ} \mathrm{C}$ with $250 \mathrm{rpm}$ shaking. For pinene production, $E$. coli was grown in a semi-defined medium (10 g/L peptone, $5 \mathrm{~g} / \mathrm{L}$ yeast extract, $5 \mathrm{~g} / \mathrm{L}$ glycerol, $2 \mathrm{~g} / \mathrm{L}$ $\mathrm{NaCl}, 0.15 \mathrm{~g} / \mathrm{L} \mathrm{MnCl}_{2}, 0.5 \mathrm{mM} \mathrm{MgCl}$, and $20 \mathrm{mM}$ phosphate buffer $\mathrm{pH} 7.0)$ at $30^{\circ} \mathrm{C}$ shaking (180 rpm). D. radiodurans $\mathrm{R} 1$ was grown in PGY broth $(5 \mathrm{~g} / \mathrm{L}$ peptone, $2 \mathrm{~g} / \mathrm{L}$ glucose, $5 \mathrm{~g} / \mathrm{L}$ yeast extract, and $1 \mathrm{~g} / \mathrm{L} \mathrm{K}_{2} \mathrm{HPO}_{4}$ ) shaking $(180 \mathrm{rpm})$ at $30{ }^{\circ} \mathrm{C}$ and on TGY agar $(5 \mathrm{~g} / \mathrm{L}$ tryptone, $1 \mathrm{~g} / \mathrm{L}$ glucose, $5 \mathrm{~g} / \mathrm{L}$ yeast extract, $1 \mathrm{~g} / \mathrm{L} \mathrm{K}_{2} \mathrm{HPO}_{4}, 15 \mathrm{~g} / \mathrm{L}$ agar) at $30{ }^{\circ} \mathrm{C}$. To evaluate $D$. radiodurans growth and pinene production with glycerol as a carbon source, first, at $30{ }^{\circ} \mathrm{C}$ with shaking $(180 \mathrm{rpm})$, we used a rich medium composed of $10 \mathrm{~g} / \mathrm{L}$ peptone, $5 \mathrm{~g} / \mathrm{L}$ yeast extract, $20 \mu \mathrm{M}$ $\mathrm{MnCl}_{2}, 1 \mathrm{mM} \mathrm{MgCl}_{2}$, and $0.18 \mathrm{mM} \mathrm{CaCl} 2$. This medium was supplemented with either $5 \mathrm{~g} / \mathrm{L}$ glycerol, $5 \mathrm{~g} / \mathrm{L}$ of glucose, or a combination of $2.5 \mathrm{~g} / \mathrm{L}$ of both of these carbon sources. For evaluating pinene production of engineered strains, the rich medium containing $5 \mathrm{~g} / \mathrm{L}$ glycerol was used in shake flasks. Then, a minimal medium with various concentrations of glycerol as the sole carbon source (10, 15 or $25 \mathrm{~g} / \mathrm{L}$ glycerol, $50 \mathrm{mg} / \mathrm{L}$ cysteine, $25 \mathrm{mg} / \mathrm{L}$ histidine, $25 \mathrm{mg} / \mathrm{L}$ methionine, $1 \% \mathrm{BME}$ vitamin mix, $20 \mu \mathrm{M}$ $\mathrm{MnCl}_{2}, 1 \mathrm{mM} \mathrm{MgCl} 2,0.18 \mathrm{mM} \mathrm{CaCl}, 10 \mathrm{~g} / \mathrm{L} \mathrm{Na}_{2} \mathrm{HPO}_{4}$, 
$\left.2 \mathrm{~g} / \mathrm{L} \mathrm{KH}_{2} \mathrm{PO}_{4}\right)$ was made, and the best strains were grown in $30^{\circ} \mathrm{C}$ shaking $(100 \mathrm{rpm})$ in shake flasks to produce pinene from glycerol as the main carbon source.. Also, different agitation speeds from 70 to $250 \mathrm{rpm}$ were tested in the rich and minimal glycerol medium. When necessary, appropriate antibiotics $(100 \mu \mathrm{g} / \mathrm{ml}$ ampicillin, $50 \mu \mathrm{g} / \mathrm{ml} \mathrm{kanamycin,} \mathrm{and} 10 \mu \mathrm{g} / \mathrm{ml}$ tetracycline for $E$. coli; $3 \mu \mathrm{g} / \mathrm{ml}$ chloramphenicol and $25 \mu \mathrm{g} / \mathrm{ml}$ kanamycin for $D$. radiodurans) were added to the medium.

\section{DNA manipulations and strain construction}

The 1785 bp coding sequence for the $A$. grandis pinene synthase was obtained from [NCBI, Accession number: AAK83564, without signal peptide], codon-optimized for expression in $D$. radiodurans, and synthesized by GenScript. The codon-optimized gene sequence is shown in Additional file 1: Fig. S1. The synthesized gene (denoted $p s_{D r}$ ), with added $\mathrm{XhoI} / \mathrm{Sacl} / \mathrm{NdeI}$ restriction sites upstream of the gene, was subcloned into the plasmid pRADN1 [25] between XhoI and BamHI sites. We decided to place the pinene synthase gene under the control of three well-known and strong promoters $\mathrm{P}_{\text {katA }}$, $\mathrm{P}_{g r o E}$, and $\mathrm{P}_{t u f A}$ often used for constitutive gene expression in $D$. radiodurans [26]. The three promoter fragments (including their associated ribosomal binding sites), were PCR-amplified using $D$. radiodurans $\mathrm{R} 1$ genomic DNA as a template. All primer sequences are listed in Additional file 1: Table S1. The promoter fragments $\mathrm{P}_{\text {katA }}$ and $\mathrm{P}_{\text {groE }}$ were inserted between $X h o I$ and $N d e l I$ and $\mathrm{P}_{t u f A}$ between $X h o \mathrm{I}$ and SacI, to yield expression vectors pRAD-kP, pRAD-gP, pRAD-tP. To make plasmids for expressing a pinene synthase-GFP fusion, we first constructed vectors with the pinene synthase gene devoid of the stop codon, essentially as described above. Next, we PCR amplified $g f p$ using the $\mathrm{pCDH} 513 \mathrm{~B}$ vector as a template and inserted it between BamHI and HindIII.

Expression of the E. coli ispA, encoding GPP synthase, was placed under the control of $\mathrm{P}_{k a t A}$. First, the promoter fragments were PCR-amplified and inserted in pRAD-kP between BamHI and $X b a \mathrm{I}$ sites. Then ispA was PCR-amplified from E. coli NM522 genomic DNA and inserted the resulting fragment between $\mathrm{Xba \textrm {I }}$ and Hin$d$ III to yield the vector pRAD-P-I. Additionally, the $\mathrm{P}_{k a t A}$ and $i s p A$ fragments were inserted in pRADN1 to obtain pRAD-I. For over-expression of the native $D$. radiodurans gene $d x s$ encoding 1-deoxy-D-xylulose-5-phosphate synthase, we amplified the $\mathrm{P}_{\text {kat }}$ promoter fragment and inserted it between HindIII and SalI in pRAD-P-I. The $d x$ sene was PCR amplified using $D$. radiodurans $\mathrm{R} 1$ genomic DNA as a template and inserted between SalI and $S d a$ I to yield the vector pRAD-P-I-D. To construct pRAD-P-D, the plasmid pRAD-P-I-D was restricted with BamHI and HindIII to remove ispA, treated with $\mathrm{S} 1$ nuclease (ThermoFisher) to remove ssDNA overhangs, and then re-ligated to yield pRAD-P-D.

It has previously been suggested that a translational fusion of pinene synthase and GPP synthase can improve the catalytic activity in pinene production [16]. To test this, we made two versions of the pinene synthase-GPP synthase fusion: one with pinene synthase in the N- terminus (Pinene synthase-linker-GPP synthase) and one with GPP synthase in the N-terminus (GPP synthaselinker-pinene synthase). In both cases, the enzymes were separated by a flexible GGGGS linker peptide. To construct the plasmids expressing these fusions, the $p s_{D r}$ and ispA genes were PCR amplified, restricted with SalI/SacI and $S a c \mathrm{I} /$ BamHI, respectively, and inserted between SalI and BamHI in pRAD-P-I-D to yield pRAD-P:G-D. The plasmid pRAD-G:P-D was made analogously.

The genes $d r 0862(c r t B)$ and $d r 1395$ encoding phytoene synthase and GPP synthase, respectively, where inactivated in $D$. radiodurans $\mathrm{R} 1$. This was done by replacing the genes with a kanamycin resistance gene transcribed from the $\mathrm{P}_{\text {kat }}$ promoter. To do so, we PCR amplified the up-and downstream regions of the genes as well as the $\mathrm{P}_{\text {kat } A}$ promoter using $D$. radiodurans $\mathrm{R} 1$ genomic DNA as a template. The kanamycin resistance gene was PCR amplified using the pET-26b plasmid as the template. Next, the fragments were inserted sequentially in pET26b (for the purpose of assembling the fragments), and finally, the full construct was used as the template for PCR with primer sets dr0862_UP fwd/ dr0862_DWN rev and dr1395_UP fwd/dr1395_Dwn rev, respectively. The PCR products were purified and used to transform $D$. radiodurans $\mathrm{R} 1$ (transformation described below). When inactivating $d r 1395$, the PCR fragment was mixed with plasmids containing the ispA gene (pRAD-I and pRADP-I-D). In the absence of isp $A$ no transformants were obtained. As both mutations were envisioned to disrupt pigment production in $D$. radiodurans, transformants without pigment production phenotype were selected on the kanamycin-containing TGY agar, and the modified chromosomal region was PCR-amplified and sequenced to confirm the gene replacement.

The pinene production strains were generated by transformation of $D$. radiodurans strains $\mathrm{R} 1, \Delta d r 0862$, and $\Delta d r 1395$ with relevant expression plasmids. All plasmids and strains are listed in Table 1.

To benchmark the constructed $D$. radiodurans strains against an E. coli pinene production strain, E. coli EcpsB strain was constructed. To do this, we subcloned the $p s_{D r}$ gene and inserted it in the pET26-b expression vector between NdeI and BamHI to generate pET26b$p s_{D r}$. Next, E. coli BL21(DE3) was co-transformed with pET26b- $p s_{D r}$ and the pMBIS plasmid encoding the mevalonate pathway from Saccharomyces cerevisiae [27]. 
Table 1 Plasmids and strains

\begin{tabular}{|c|c|c|}
\hline Name & Description & Source \\
\hline \multicolumn{3}{|l|}{ Plasmids } \\
\hline pRADN1 & E. coli-D. radiodurans shuttle vector, chloramphenicol resistance & Hirofumi Ohba et al., 2005 \\
\hline pET-26b & E. coli expression vector, kanamycin resistance & Novagen \\
\hline pMBIS & E. coli mevalonate pathway vector & Martin et al., 2003 \\
\hline pET26b-ps $s_{D r}$ & $\mathrm{pET}-26 \mathrm{~b}-p s_{D r}$ & This study \\
\hline pRAD-kP & pRADN1-P ${ }_{k a t A}-p s_{D r}$ & This study \\
\hline pRAD-gP & pRADN1-P ${ }_{g r o E}-p s_{D r}$ & This study \\
\hline pRAD-tP & PRADN1-P ${ }_{t u f A}-P S_{D r}$ & This study \\
\hline pRAD-P-I & pRADN1-P ${ }_{k a t A}-P s_{D r}-P_{k a t A}-i s p A$ & This study \\
\hline pRAD-P-I-D & pRADN1-P ${ }_{k a t A}-P s_{D r}-P_{k a t A}-i s p A-P_{k a t A}-d x s$ & This study \\
\hline pRAD-P-D & pRADN1-P ${ }_{k a t A}-P s_{D r}-P_{k a t A}-d x s$ & This study \\
\hline pRAD-I & pRADN1-P katA $-i s p A$ & This study \\
\hline pRAD-P:G-D & pRADN1-P katA $-p s_{D r}$ ispA-P katA $-d x s$ & This study \\
\hline pRAD-G:P-D & pRADN1-P katA $-i s p A: p s_{D r}-P_{k a t A}-d x s$ & This study \\
\hline pET-26b- dr0862:::kan ${ }^{R}$ & pET-26b-dr0862::kan ${ }^{R}$ & This study \\
\hline pET-26b- dr1395::kan ${ }^{R}$ & pET-26b-dr1395::kan ${ }^{R}$ & This study \\
\hline \multicolumn{3}{|l|}{ Strains } \\
\hline E. coli BL21(DE3) & $\mathrm{F}^{-}$ompT hsdSB (rB $\left.{ }^{-} \mathrm{mB}\right)^{-}$gal dem rne131 $\lambda(\mathrm{DE} 3)$ & Invitrogen \\
\hline E. coli NM522 & supE, thi, $\Delta\left(\text { lac-proAB), hsd5 (r, }{ }^{-} \mathrm{m}\right)^{-}$ & Promega \\
\hline D. radiodurans R1 & wild type & ATCC 13,939 \\
\hline WT kP & D. radiodurans pRAD-kP & This study \\
\hline WT gP & D. radiodurans pRAD-gP & This study \\
\hline WT tP & D. radiodurans $\mathrm{pRAD}-\mathrm{tP}$ & This study \\
\hline WT P-I & D. radiodurans pRAD-P-I & This study \\
\hline WT P-I-D & D. radiodurans pRAD-P-I-D & This study \\
\hline$\Delta d r 1395$ । & D. radiodurans $\triangle d r 1395$ pRAD-I & This studys \\
\hline$\Delta d r 1395 \mathrm{P}-\mathrm{I}$ & D. radiodurans $\triangle d r 1395$ pRAD-P-I & This study \\
\hline$\Delta d r 1395$ P-I-D & D. radiodurans $\Delta d r 1395$ pRAD-P-I-D & This study \\
\hline$\triangle d r 0862$ & D. radiodurans $\triangle d r 0862$ & This study \\
\hline$\triangle d r 0862 \mathrm{kP}$ & D. radiodurans $\triangle d r 0862$ pRAD-P & This study \\
\hline$\triangle d r 0862 \mathrm{P}-\mathrm{I}$ & D. radiodurans $\triangle d$ dr0862 pRAD-P-I & This study \\
\hline$\triangle d r 0862 \mathrm{P}-\mathrm{D}$ & D. radiodurans $\triangle$ dr0862 pRAD-P-D & This study \\
\hline$\Delta d r 0862$ P-I-D & D. radiodurans $\triangle$ dr0862 pRAD-P-I-D & This study \\
\hline$\triangle d r 0862$ P:G-D & D. radiodurans $\triangle d r 0862$ pRAD-P:G-D & This study \\
\hline$\triangle d r 0862 \mathrm{G}: \mathrm{P}-\mathrm{D}$ & D. radiodurans $\triangle$ dr0862 pRAD-G:P-D & This study \\
\hline E. coli EcpsB & E. coli BL21 pMBIS pET26b-ps $s_{D r}$ & This study \\
\hline
\end{tabular}

$1 \mathrm{mM}$ IPTG added for gene expression induction and pinene production in E. coli EcpsB. Whereas the $p s_{D r}$ gene was codon optimized for expression in $D$. radiodurans, production of the enzyme in $E$. coli was confirmed by SDS-PAGE (Additional file 1: Fig. S5).

\section{Deinococcus radiodurans transformation}

The transformation was performed using a modified calcium chloride method [28]. Briefly, D. radiodurans was grown in PGY at $30{ }^{\circ} \mathrm{C}$ and agitation speed of $180 \mathrm{rpm}$ for $24 \mathrm{~h} .100 \mu \mathrm{l}$ of the bacterial culture was added to a new
$5 \mathrm{~mL}$ of PGY and grown at $30{ }^{\circ} \mathrm{C}$ and $180 \mathrm{rpm}$ shaking to reach $\mathrm{OD}_{600}$ of $0.4 .1 .5 \mathrm{~mL}$ of the cell culture was centrifugated, and the supernatant was discarded. The cell pellet was resuspended in $100 \mu \mathrm{L}$ of the liquid PGY plus $40 \mu \mathrm{L}$ of $0.3 \mathrm{M}$ calcium chloride and aliquoted in $30 \mu \mathrm{L}$ microtubes. $10 \mu \mathrm{l}$ of the target plasmid $(1-2 \mu \mathrm{g})$ or purified amplicon $(0.2-0.6 \mu \mathrm{g})$ was added to the microtubes and mixed by gentle pipetting. This mixture was placed on ice for $15 \mathrm{~min}$ and then placed in a $30^{\circ} \mathrm{C}$ incubator for $2 \mathrm{~h}$. Subsequently, $1 \mathrm{~mL}$ PGY was added to the bacteria, and the mix was further incubated at $30{ }^{\circ} \mathrm{C}$ for $24 \mathrm{~h}$. After 
this incubation, the mix was plated on TGY agar plates containing chloramphenicol/kanamycin (or both) and was incubated at $30^{\circ} \mathrm{C}$ for $72 \mathrm{~h}$.

\section{Confirmation of gene expression from groE, katA and tufA promoters}

The Real-time PCR method was performed to confirm that the promoters were functional, leading to transcription of the pinene synthase gene. RNA extraction, cDNA synthesis, and SYBR green qPCR were performed with the corresponding kits according to the manufacturer's instructions (Pars Toos Co.). The primer sets Ps-RT fwd/ rev and Gap-RT fwd/rev were used for the amplification of pinene synthase gene and the housekeeping gene (glyceraldehyde 3-phosphate dehydrogenase (dr1343)), respectively.

Moreover, to confirm the presence of the pinene synthase in the cell, we grew $D$. radiodurans expressing pinene synthase fused to GFP, for $24 \mathrm{~h}$ in PGY medium at $30{ }^{\circ} \mathrm{C}$ shaking at $180 \mathrm{rpm}$. The expression of pinene synthase-GFP fusion was visualized using fluorescence microscopy (Leica DM, 4000 B).

\section{Pinene toxicity assay}

To investigate the toxicity of $\alpha$ - and $\beta$-pinene, engineered pinene producing strains $D$. radiodurans ( $\triangle$ dr0862 P-I-D strain) and E. coli EcpsB were cultivated in the presence of exogenous pinene in a microtiter plate. These strains were cultivated in the rich medium broth at $30{ }^{\circ} \mathrm{C}$ and $180 \mathrm{rpm}$ agitation speed for $24 \mathrm{~h}$ and inoculated the rich medium to a starting $\mathrm{OD}_{630}$ of 0.02 . Different concentrations of $\alpha$ - and $\beta$-pinene $(1,1.75,2.5$, and $5 \mathrm{~g} / \mathrm{L})$ were added to the medium and incubated at $30{ }^{\circ} \mathrm{C}$ with shaking speed set to "medium" in a microplate reader (BioTek, ELx808). The growth of different strains was determined by measuring $\mathrm{OD}_{630}$ every $30 \mathrm{~min}$ for $48 \mathrm{~h}$.

\section{Testing the ability of $D$. radiodurans to metabolize pinene}

To determine the ability of $D$. radiodurans to metabolize $\alpha$ - and $\beta$-pinene, the rich medium with $10 \% \mathrm{v} / \mathrm{v}$ dodecane was supplemented with $20 \mathrm{mg} / \mathrm{L} \alpha$ - and $\beta$-pinene. $D$. radiodurans was inoculated to $\mathrm{OD}_{600} 0.02$ and cultured for 5 days at $30^{\circ} \mathrm{C}$ and $180 \mathrm{rpm}$ shaking. Thereafter, $0.5 \mathrm{~mL}$ of the dodecane layer was transferred to a $1.5 \mathrm{ml}$ microcentrifuge tube and centrifuged at $14,000 \mathrm{~g}$ for $5 \mathrm{~min}$ to precipitate debris. The upper layer was placed in a new microtube, and this sample was analyzed by GC-FID as described below. The obtained results were compared with those of bacterium-free and the dodecane layer with added pinene isomers before fermentation.

\section{Pinene sample preparation}

We assessed the pinene extraction in various dodecane concentrations (10 and 20\%) in the rich and minimal glycerol medium. Regarding the fermentation for the pinene production, $1 \mathrm{~mL}$ of a 24-h old bacterial culture was added to $50 \mathrm{~mL}$ of fresh growth medium and incubated at $30{ }^{\circ} \mathrm{C}$ and $180 \mathrm{rpm}$ shaking for the rich and $100 \mathrm{rpm}$ for minimal glycerol medium. When the $\mathrm{OD}_{600}$ reached 3 for $D$. radiodurans and 1 for $E$. coli, $10 \% v / v$ dodecane for the rich medium (180 rpm shaking) and $20 \%$ for minimal glycerol medium (100 rpm shaking) was added to extract pinene. The dodecane layer was sampled after 24,48 , and $72 \mathrm{~h}$, and the pinene recovered therein was measured through GC [29].

\section{GC-FID and GC-MS analysis}

Pinene production by $D$. radiodurans and $E$. coli was measured by gas chromatography (GC). To this end, $0.5 \mathrm{~mL}$ of the dodecane layer from a shake flask culture was transferred to a $1.5 \mathrm{ml}$ microcentrifuge tube and was then centrifuged at $14,000 \mathrm{~g}$ for $5 \mathrm{~min}$ to precipitate debris. The upper layer was placed in a new microtube, and $1 \mu \mathrm{l}$ of that was injected into GC-FID or GC-MS. Moreover, to analyze the intracellular presence of produced pinene, the biomass of pinene production fermentation was separated by centrifugation in $10.000 \mathrm{~g}$ for $10 \mathrm{~min}$, and $5 \mathrm{ml}$ dodecane was added to the biomass. After vortexing vigorously, the cells were lysed by sonication ( $20 \mathrm{~s}$ sonication $/ 5 \mathrm{~s}$ rest for $15 \mathrm{~min}$ on ice). Afterwards, $0.5 \mathrm{~mL}$ of the dodecane was transferred to a $1.5 \mathrm{ml}$ microcentrifuge tube and was centrifuged at $14,000 \mathrm{~g}$ for $5 \mathrm{~min}$ to precipitate debris. The upper layer dodecane was transferred to a new microtube and was analyzed by GC-FID.

For optimization and finding the retention time, $\alpha$ - and $\beta$-pinene molecules (Sigma Co.) were used as the standard samples. In addition, to quantify the production rate, various pinene concentrations were injected into the GCFID device to plot the standard curve.

The GC-FID (Thermo Scientific Trace 1300) was used with a BPX-5 column $(30 \mathrm{~m} 0.22 \mathrm{~mm} \times 0.25 \mu \mathrm{m})$. The inlet temperature was set to $300{ }^{\circ} \mathrm{C}$, purge flow $5 \mathrm{ml} /$ $\mathrm{min}$, split flow at $180 \mathrm{ml} / \mathrm{min}$, the oven at $50^{\circ} \mathrm{C}$ for $1 \mathrm{~min}$, ramp at $50{ }^{\circ} \mathrm{C} / \mathrm{min}$ to $250{ }^{\circ} \mathrm{C}$.

The produced pinene molecule, by engineered strains, was confirmed by GC-MS. For the GC-MS, samples were analyzed by a gas chromatography system (Thermo Scientific Trace 1300) coupled to a single quadrupole mass spectrometer (Thermo Scientific ISQ 7000). Split injection was used, with a ratio of 20:1 with an inlet temperature of $300{ }^{\circ} \mathrm{C}$. The carrier gas was helium, and the inlet flow was set at $2 \mathrm{~mL} \cdot \mathrm{min}^{-1}$ throughout the run. 
The gas chromatography system was equipped with a Thermo Scientific TraceGOLD TG-5MS column (length: $30 \mathrm{~m}$; diameter: $0.25 \mathrm{~mm}$; film thickness: $0.25 \mu \mathrm{m}$ ), and the following temperature gradient was utilized: Initial temperature of $40{ }^{\circ} \mathrm{C}$ held for $10 \mathrm{~min}$, raised to $250{ }^{\circ} \mathrm{C}$ at $50{ }^{\circ} \mathrm{C} \mathrm{min}{ }^{-1}$, and then held at $250{ }^{\circ} \mathrm{C}$ for $8 \mathrm{~min}$. Electron impact ionization was used with the mass detector set to $30-600 \mathrm{~m} / \mathrm{z}$. The transfer line was held at a constant $280^{\circ} \mathrm{C}$, and the ion source temperature was $300^{\circ} \mathrm{C}$.

\section{Results and discussion}

\section{Potential of $D$. radiodurans as a pinene production host}

In the present study, we investigated the potential of using $D$. radiodurans as a novel host for the production of the monoterpene molecule pinene using glycerol as a substrate. We hypothesized that $D$. radiodurans could be particularly well suited due to the fact that it produces a pigment, deinoxanthin, that like pinene is synthesized from GPP. Further, D. radiodurans shows resistance to many types of stress, and we considered the possibility that it would have a higher inherent resistance to pinene and GPP than, for example E. coli. Additionally, D. radiodurans has relatively high intracellular concentration of manganese $(0.2-4 \mathrm{mM})$, which is the main cofactor for the pinene synthase enzyme [22].

As a first step, we attempted to construct a basic pinene production strain. The precursor for pinene is GPP. This molecule is produced via the native non-mevalonate pathway, where it acts as a precursor for the pigment molecule deinoxanthin. Conversion of GPP to pinene is catalyzed by pinene synthase. Several pinene synthases have previously been described, and we selected the pinene synthase from $A$. grandis that was shown to be functional in $E$. coli [16]. The coding sequence was codon-optimized for $D$. radiodurans and placed under the control of the three promoters $\mathrm{P}_{k a t A}, \mathrm{P}_{g r o E}$, and $\mathrm{P}_{t u f A}$ that have been employed previously for gene expression in $D$. radiodurans $[26,30]$. We then cultured these strains (WT kP, WT gP, and WT tP) for $72 \mathrm{~h}$ in the rich medium containing glycerol, but pinene was not detected in the fermentation broth. To assure that the genes were expressed, we performed real-time PCR. This demonstrated that the genes were in fact transcribed, but also that the mRNA levels were similar for all three promoters (Fig. 1a). The use of the promoter $\mathrm{P}_{k a t A}$ has been reported previously $[26,28]$. Considering that the difference between that and the other promoters tested was minimal, we decided to use $\mathrm{P}_{\text {katA }}$ for all subsequent genetic constructs. To assure that the pinene synthase protein was also present in the cell, we expressed a pinene synthase variant tagged with GFP in the C-terminus. Our fluorescence microscopy analysis confirmed that the protein was indeed produced in the cells (Fig. 1b).

\section{Metabolic engineering strategy for pinene production in $D$. radiodurans}

Our initial efforts demonstrated that the successful expression of pinene synthase is not sufficient to produce detectable levels of pinene. Since we had no reason to doubt that the expressed pinene synthase is functional, we considered different possible explanations based on the known metabolic pathways in D. radiodurans (Fig. 2).
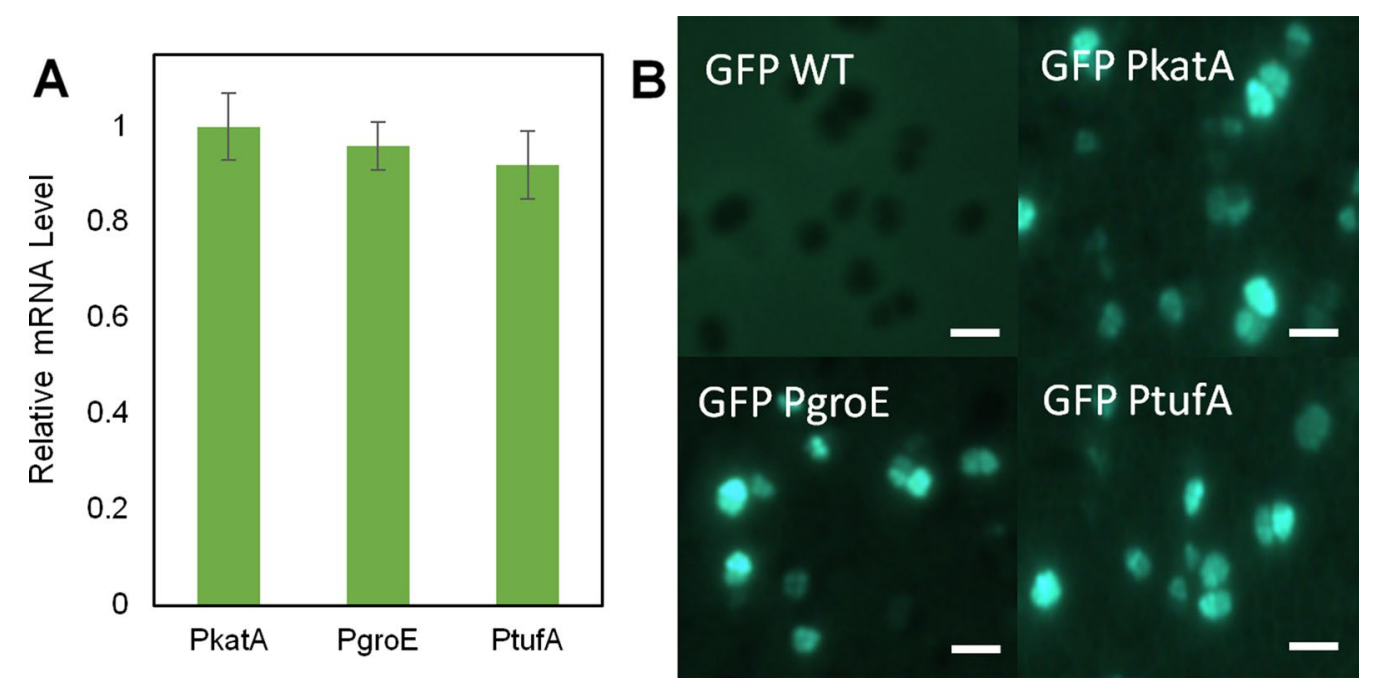

Fig. 1 Pinene synthase-encoding gene is expressed in wild type $D$. radiodurans cells. a The expression levels from three different promoters $P_{\text {katA, }}$ $P_{\text {groe }}$ and $P_{\text {tufa }}$ were analysed by real-time $P C R, \mathbf{b}$ and the presence of pinene synthase was confirmed using a construct expressing the pinene synthase gene fused to $\mathrm{gfp}$. Fluorescence in the cells was observed by fluorescence microscopy. Scale bars: $4 \mu \mathrm{m}$ 


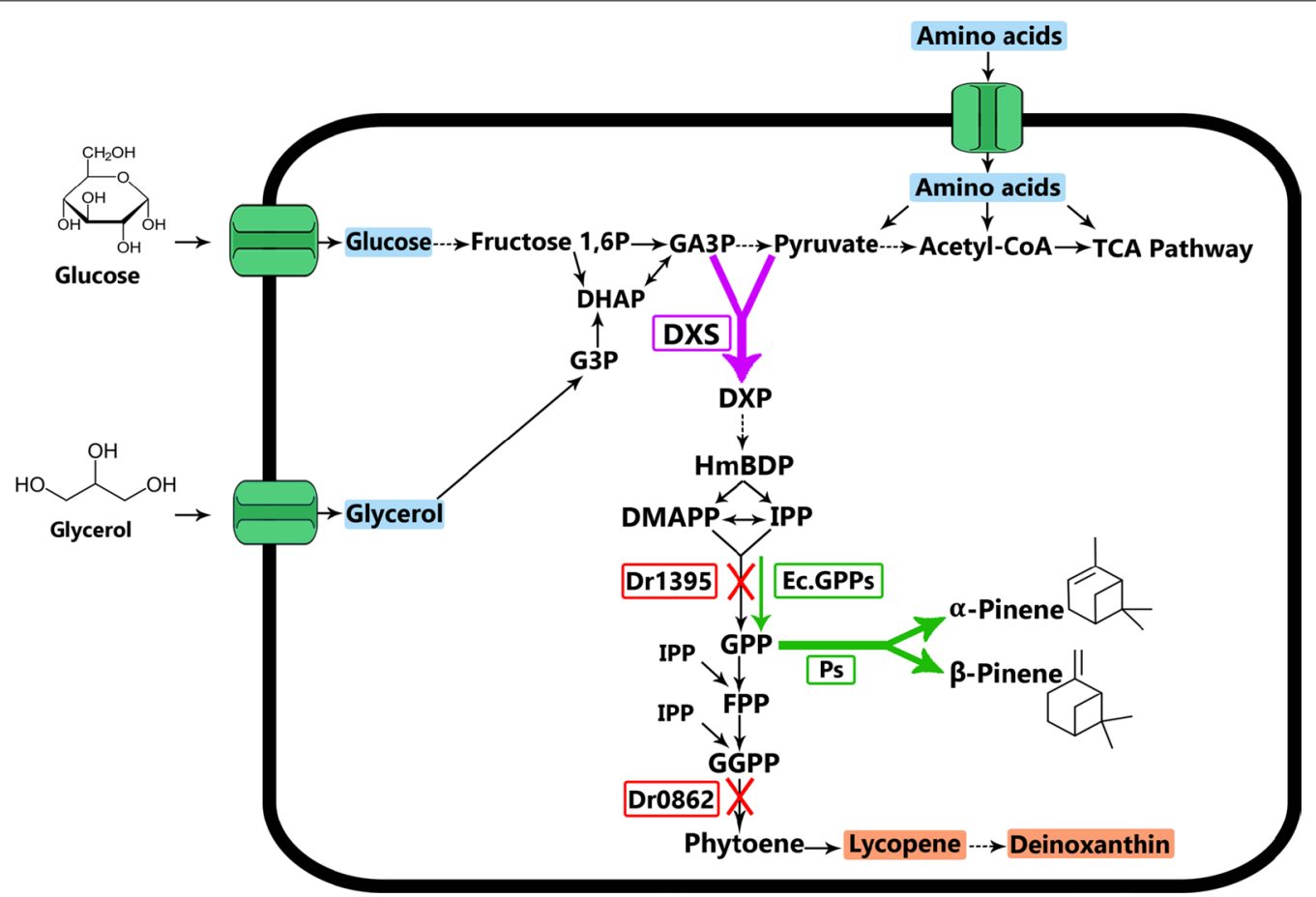

Fig. 2 Schematic representation of the pinene production strategy and modifications to enhance the production in D. radiodurans. D. radiodurans carbohydrate sources including glycerol, glucose, and amino acids catabolism and pyruvate (Pyr) production in the cell. Pyr with glyceraldehyde 3-phosphate (GA3P) is converted to 1-Deoxy-D-Xylulose 5-Phosphate (DXP) by the enzyme 1-deoxy-D-xylulose-5-phosphate synthase (DXS). Following this pathway, isopentenyl diphosphate (IPP) and dimethylallyl diphosphate (DMAPP) molecules are produced. Afterward, GPP synthase produces a GPP molecule from these two molecules. Finally, pinene synthase (Ps) catalyzes synthesis of pinene by cyclizing GPP. Black arrows indicate the natural path inside the cell; purple arrows indicate overexpression in the pathway; green arrows indicate heterologous expression, and the cross sign indicates the inactivation of the gene in the cell. The abbreviations of the pathway are as follows: Ec. GPPs, E. coli GPP synthase gene; Dr1395, native GPP synthase; Dr0862, native phytoene synthase

It is evident that the native GPP synthase plays an important role in the process by catalyzing the synthesis of GPP. While D. radiodurans is known to produce sufficient amounts of GPP for deinoxanthin production, there is a possibility that the GPP pool is drained by the subsequent reactions in the deinoxanthin pathway: condensation of GPP units to produce farnesyl pyrophosphate (FPP) and geranylgeranyl pyrophosphate (GGPP). These reactions are consuming GPP and are therefore competing with pinene synthesis for the substrate GPP.

Liu and coworkers previously indicated thatthe GPP synthase is essential in $D$. radiodurans, but could be inactivated when complemented with E. coli GPP synthase IspA that does not catalyze GGPP synthesis [31]. Their results showed GPP and FPP, as well as GGPP, are the main products of the native GPP synthase enzyme in $D$. radioduran, and the native GPP synthase does not only produce GGPP. Therefore, such a strain without producing GGPP should be beneficial for pinene production, as it preserves the GPP pool and high amount of carbon flux by abolishing deinoxanthin synthesis.
An alternative way to prevent deinoxanthin production without deleting of the native GPP synthase in $D$. radiodurans would be via the inactivation of phytoene synthase that catalyzes the conversion of GGPP to phytoene. In case the synthesis of GPP from DMAPP and IPP would be a bottleneck, expression of the GPP synthase IspA should also lead to an increase in the GPP pool. Finally, Previous studies have shown that using heterologous mevalonate pathway could enhance the GPP pool and terepene production in E. coli [15], but studies on non-mevalonate pathway in D. radiodurans showed this pathway is highly active, and we decided to boost this native pathway. One could consider improving the flux through the entire pathway by overexpressing DXS to direct more GA3P and pyruvate through the pathway via DXP synthesis. Based on this analysis, we decided to inactivate the genes encoding GPP synthase and phytoene synthase and to make plasmids for the expression of pinene synthase and GPP synthase IspA and/or DXS. 


\section{Evaluation of engineered $D$. radiodurans strains for pinene} production

Based on our analysis of the metabolism of $D$. radiodurans, we constructed a number of strains that, besides the expression of pinene synthase, expressed E. coli GPP synthase and/or overexpressed DXS. This was done in wild type as well as in strains where either the native GPP synthase $(\Delta d r 1395)$ or the phytoene synthase $(\Delta d r 0862)$ was inactivated. These strains were subsequently tested for pinene production in the rich medium by GC-FID, and pinene isomers confirmed in the final samples by GC-MS (Table 2 and Fig. 3).

As mentioned above, expression of $A$. grandis pinene synthase in the wild type strain (WT kP) did not lead to

Table 2 Pinene production in D. radiodurans after $72 \mathrm{~h}$ of shake flask fermentation

\begin{tabular}{|c|c|c|c|c|c|}
\hline Host & $\begin{array}{l}\text { Plasmid-expressed } \\
\text { proteins }\end{array}$ & $\begin{array}{l}\text { Titer } \\
{[\mathrm{mg} / \mathrm{L}]}\end{array}$ & $\begin{array}{l}\text { Productivity } \\
\text { [ug pinene/h] }\end{array}$ & $\begin{array}{l}\text { Yield } \\
\text { [mg pinene/g } \\
\text { glycerol] }\end{array}$ & Medium \\
\hline \multirow[t]{2}{*}{ WT } & PS-IspA & $0.5 \pm 0.1$ & 7 & - & Rich Medium \\
\hline & PS-IspA-DXS & $0.7 \pm 0.1$ & 10 & - & Rich Medium \\
\hline \multirow[t]{2}{*}{$\Delta d r 1395$} & PS-IspA & $1.4 \pm 0.2$ & 19 & - & Rich Medium \\
\hline & PS-IspA-DXS & $1.8 \pm 0.2$ & 25 & - & Rich Medium \\
\hline \multirow[t]{6}{*}{$\Delta d r 0862$} & PS-IspA & $2.1 \pm 0.1$ & 29 & - & Rich Medium \\
\hline & PS-DXS & $0.6 \pm 0.1$ & 8 & - & Rich Medium \\
\hline & PS:IspA-DXS & $1.7 \pm 0.1$ & 24 & - & Rich Medium \\
\hline & IspA:PS-DXS & $2.4 \pm 0.2$ & 33 & - & Rich Medium \\
\hline & PS-IspA-DXS & $2.6 \pm 0.2$ & 36 & - & Rich Medium \\
\hline & PS-IspA-DXS & $3.2 \pm 0.2$ & 45 & 0.13 & Minimal Glycerol Medium \\
\hline E. coli EcpsB & MEV-PS & $0.9 \pm 0.2$ & 13 & - & Rich Medium \\
\hline E. coli EcpsB & MEV-PS & $0.65 \pm 0.1$ & 9 & 0.026 & Minimal Glycerol Medium \\
\hline
\end{tabular}

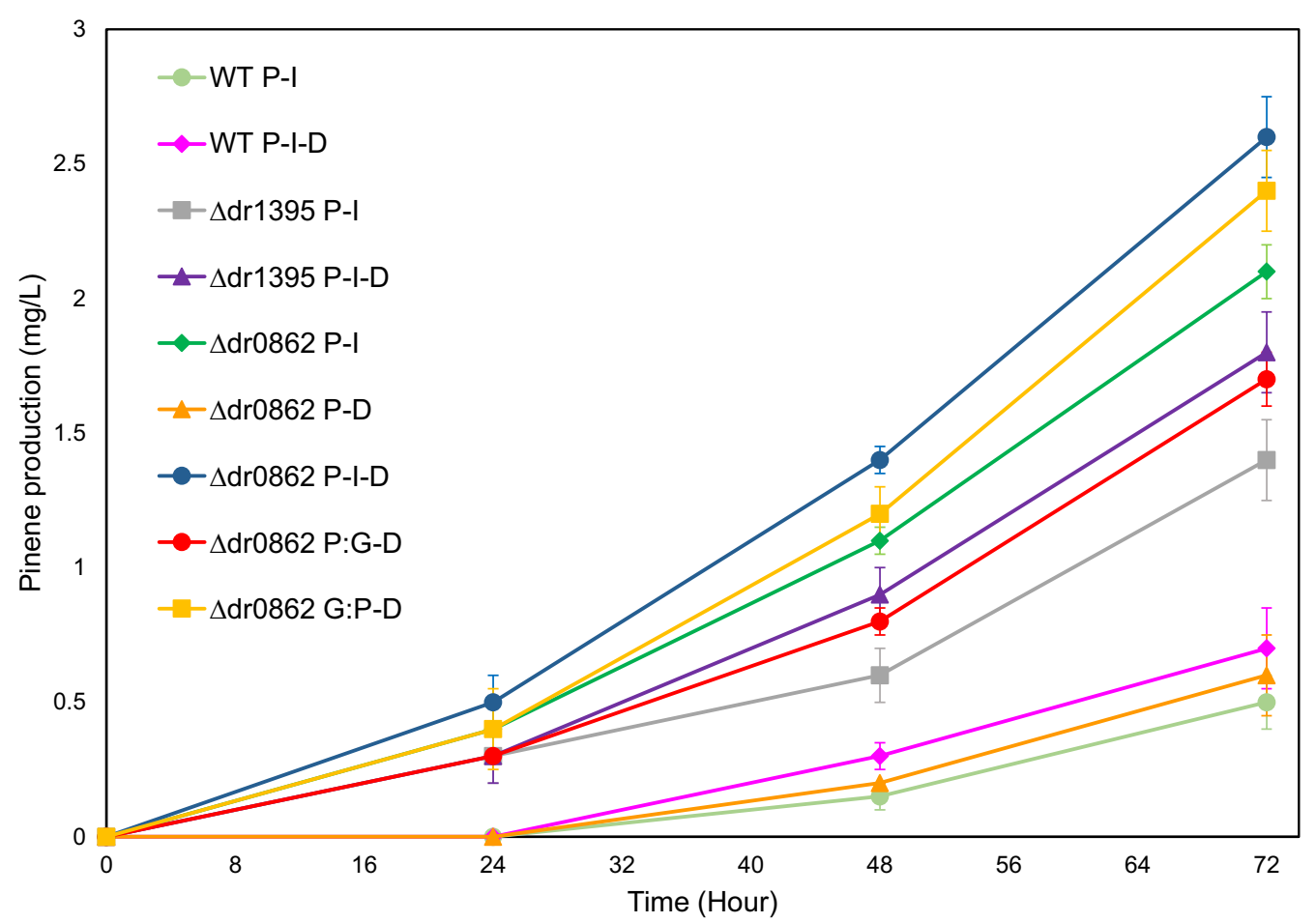

Fig. 3 The amounts of pinene produced by different recombinant D. radiodurans strains during $72 \mathrm{~h}$ of growth in the rich medium supplemented with glycerol, in shake flasks 
the production of detectable levels of pinene. When $E$. coli GPP synthase was introduced (WT P-I), we detected production of $0.5 \mathrm{mg} / \mathrm{L}$ of pinene. This would seem to indicate that the GPP pool was not sufficient in the strain (WT kP), and that conversion of DMAPP and IPP to GPP indeed presented a bottleneck for pinene production.

We then overexpressed DXS in this strain, resulting in strain WT P-I-D, which was expected to increase the production of 1-deoxy-D-xylulose-5- phosphate (DXP) from pyruvate $(\mathrm{Pyr})$ and 3-glyceraldehyde phosphate (GA3P), and thereby increase the flux through the nonmevalonate pathway. It has previously been shown that among the enzymes of this pathway, only overexpression of this enzyme can increase the production of GPP and carotenoids in $D$. radiodurans significantly [32], but in our experiments, it did not lead to a significantly higher pinene titer.

Previous studies have shown that the non-mevalonate pathway in $D$. radiodurans can support the production of $203.5 \mathrm{mg} / \mathrm{g}$ dried cell weight of carotenoid molecules in fed-batch fermentation [32]. These results indicate a high flow rate of GPP into the carotenoid pathway that leads to deinoxanthin production. Consequently, it should be beneficial with respect to pinene synthesis to disrupt this pathway. To test this, we constructed two strains where genes encoding the native GPP synthase $(d r 1395)$ and the phytoene synthase (dr0862), respectively, were inactivated. As mentioned above, the dr1395 mutant could only be constructed when complemented with the $E$. coli GPP synthase. By expressing the pinene synthase, this strain $(\Delta d r 1395 \mathrm{P}-\mathrm{I})$ enabled the production of $1.8 \mathrm{mg} / \mathrm{L}$ of pinene, which was a 3.6 fold improvement compared to the titer obtained in the wild type background (WT P-I). When further overexpressing the DXS enzyme, in strain $\Delta d r 1395$ P-I-D we recorded a slightly higher titer, but the difference was not statistically significant. As mentioned above, the substitution of $D$. radiodurans GPP synthase with that of $E$. coli prevents the formation of GGPP, which feeds into the deinoxanthin biosynthesis pathway. It thus prevents draining the GPP pool via deinoxanthin synthesis, but also prevents the possible buildup of GGPP. On the other hand, it might reduce the amount of GPP.

To perform a more direct inactivation of the deinoxanthin pathway, we inactivated the gene dr0862, encoding phytoene synthase. When evaluating pinene production of this strain expressing pinene synthase and E. coli GPP synthase $(\Delta d r 0862 \mathrm{P}-\mathrm{I})$, we saw a further increase in titer to $2.1 \mathrm{mg} / \mathrm{L}$, which was a 1.5 -fold increase compared to that observed in the $d r 1395$ mutant $(\Delta d r 1395 \mathrm{P}-\mathrm{I})$. This would suggest that the primary beneficial effect of the mutations is the prevention of deinoxanthin formation and not preventing the conversion of GPP to FPP and
GGPP catalyzed by the $D$. radiodurans GPP synthase per se. In this strain, the additional expression of DXS $(\Delta d r 0862$ P-I-D) to increase flux through the non-mevalonate pathway led to a small but significant increase in pinene titer $(2.6 \mathrm{mg} / \mathrm{L})$.

Previous reports have shown that expression of fusion forms of pinene synthase and GPP synthase resulted in increased pinene production in $E$. coli, with the fusion form containing pinene synthase in the $\mathrm{C}$-terminus increasing the titer by sixfold [16]. We constructed versions of fusion proteins containing $A$. grandis pinene synthase (in either $\mathrm{N}$ - or C-terminus) and E. coli GPP synthase. Then we tested the performance of the fusion proteins in the dr0862 mutant overexpressing DXS ( $\Delta d r 0862$ P:I-D and $\Delta d r 0862$ I:P-D). Both fusion proteins were active (at least with respect to pinene synthase activity). As in $E$. coli, the variant containing C-terminal pinene synthase ( $\Delta d r 0862$ I:P-D) performed best, but it did not lead to a further improvement in pinene titer.

For initial evaluation of the engineered strains, we used a rich medium supplemented with glycerol. To rule out the possibility that glycerol could be an inferior substrate, we compared the growth and pinene production in various media where glycerol was substituted with either glucose or a mix of glycerol and glucose (Fig. 4). This demonstrated that glycerol in the medium supported a higher pinene titer than did glucose.

\section{Pinene resistance and degradation in $D$. radiodurans}

Previous investigations have revealed that pinene is toxic for fungi and bacteria. Pinene minimal microbicidal concentrations for various species such as Cryptococcus neoformans $(0.12 \mathrm{~g} / \mathrm{L})$, Candida albicans (3.12 g/L), methicillin-resistant Staphylococcus aureus (4.15 g/L), and Corynebacterium glutamicum $(<2.5 \mathrm{~g} / \mathrm{L})$ are reported, which show high toxicity of this monoterpene on microorganisms [29, 33, 34]. On the other hand, pinene toxicity has been reported as one of the main problems for producing pinene by microbial cell factories [16]. Also, enhancing the pinene resistance by overexpression of efflux pumps in $E$. coli and mutagenesis in the strain caused improvement in pinene production by E. coli [17].

Considering the possibility that pinene production would be affected due to its toxic effect, we found it relevant to investigate the pinene tolerance in the $D$. radiodurans $\Delta d r 0862$ P-I-D strain. This was done by adding exogenous pinene isomers to the medium in concentrations between 1 and $5 \mathrm{~g} / \mathrm{L}$ of pinene isomers. We also assessed E. coli EcpsB strain, grown in the same medium, in order to compare the strains in terms of pinene resistance. Growth was followed for $48 \mathrm{~h}$, and the most obvious effect of pinene was an extended lag-phase for the 

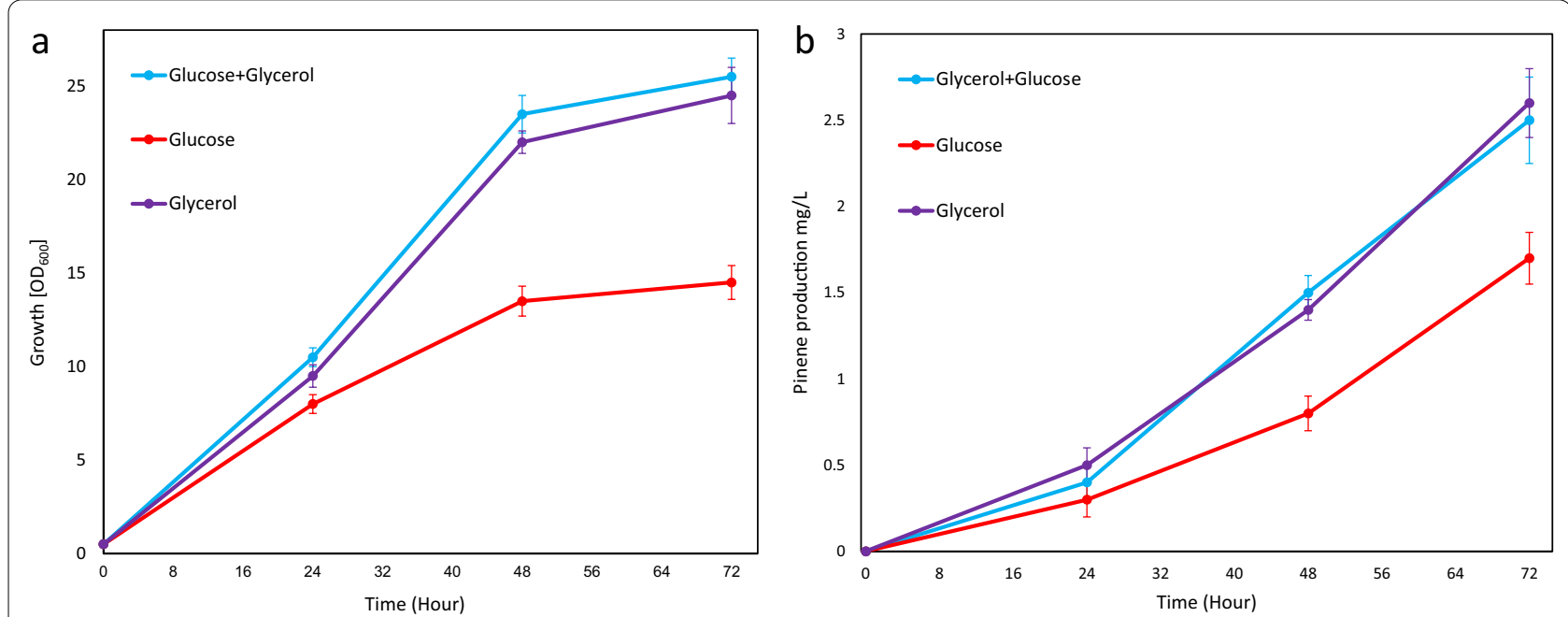

Fig. $4 \mathbf{a}$ Growth and $\mathbf{b}$ the pinene production of $D$. radiodurans in glucose- and glycerol-supplemented media. D. radiodurans was grown in a rich medium supplemented with $5 \mathrm{~g}$ glucose, $5 \mathrm{~g}$ glycerol, $2.5 \mathrm{~g}$ of each for a period of $72 \mathrm{~h}$ in shake flasks at $30^{\circ} \mathrm{C}$. All the experiments were done in biological triplicates

cells. D. radiodurans showed high resistance to $\alpha$-pinene, and growth was only mildly affected at the highest tested concentration $(5 \mathrm{~g} / \mathrm{L})$. In contrast, the E. coli EcpsB strain was strongly affected even at the lowest concentration used $(1 \mathrm{~g} / \mathrm{L})$ with a $14 \mathrm{~h}$ longer lag phase. For both strains, $\beta$-pinene was more toxic. In case of $D$. radiodurans, at $1 \mathrm{~g} / \mathrm{L}$ a slight increase in the lag phase, which was exacerbated to a $12 \mathrm{~h}$ increase in the lag phase at $5 \mathrm{~g} / \mathrm{L}$. For $E$. coli, $\beta$-pinene increased the lag phase (slightly more than $\alpha$-pinene) at the lower concentrations, and completely inhibited growth at a concentration of $2.5 \mathrm{~g} / \mathrm{L}$ (Fig. 5).

The results however revealed that $D$. radiodurans possesses a relatively high tolerance to $\alpha$ - and $\beta$-pinene. It is evident from the tolerance data that the amount of the pinene produced by $D$. radiodurans $\Delta d r 0862$ P-I-D strain is well below the inhibitory concentration and thus would be unlikely to negatively affect the pinene production. Also, our E. coli pinene production strain, exhibited a higher sensitivity to pinene than $D$. radiodurans. In a previous study, Sarria et al. reported that $E$. coli shows resistance to $\alpha$-pinene concentrations below $4.3 \mathrm{~g} / \mathrm{L}$, and that $\beta$-pinene (up to $10 \mathrm{~g} / \mathrm{L}$ ) showed no effect on its growth. Conversely, our results indicated that both $\alpha$ and $\beta$-pinene inhibit the growth of $E$. coli EcpsB. The reason for this discrepancy is presently not known but could perhaps reside in differences in growth conditions.

Monoterpene molecules have different effects on cells, which can cause toxicity impacts. Among them, inhibition of enzymes activity, preventing biofilm formation, reducing mitochondrial activity in mammalian cells [33], and membrane fluidization changes [35] are well studied. Based on the knownmechanisms of monoterpene toxicity on different cells, various protein protection and antistress mechanisms in D. radiodurans plus the particular multilayered structure of its membrane and cell wall could be the reason for the observed higher tolerance [22].

To rule out the possibility that pinene was metabolized in the cell, we conducted long-term fermentation experiments $(120 \mathrm{~h})$ where $\alpha$ - and $\beta$-pinene were added to the $D$. radiodurans growth medium. As the amount of pinene measured throughout the entire experiment was almost identical to that of the control sample, not inoculated with $D$. radiodurans, we concluded that pinene is not metabolized (Additional file 1: Fig. S2).

Moreover, to study the possibility of pinene accumulating in the cells, we resuspended the biomass after fermentation in dodecane and disrupted the cells by sonication. GC-FID analysis of the samples did not allow detection of pinene, suggesting that most or all of the produced pinene was transferred to the extracellular medium.

\section{Pinene production in minimal glycerol medium}

Next, we wanted to assess whether pinene could also be produced in a minimal medium with glycerol as the primary carbon source. To this end, we made a minimal medium consisting $25 \mathrm{~g} / \mathrm{L}$ of glycerol devoid of the complex carbon sources peptone and yeast extract. In this medium, the best pinene producing strain $D$. radiodurans $\Delta d r 0862 \mathrm{P}-\mathrm{I}-\mathrm{D}$ produced $3.2 \mathrm{mg} / \mathrm{L}$ of pinene with a yield of $0.13 \pm 0.04 \mathrm{mg} / \mathrm{g}$ glycerol and productivity of $45 \mu \mathrm{g}$ pinene/h in $72 \mathrm{~h}$ in shake flasks (Table 2). Moreover, we tested different concentrations of glycerol $(10,15$, and $25 \mathrm{~g} / \mathrm{L}$ ) in the minimal medium to evaluate pinene 

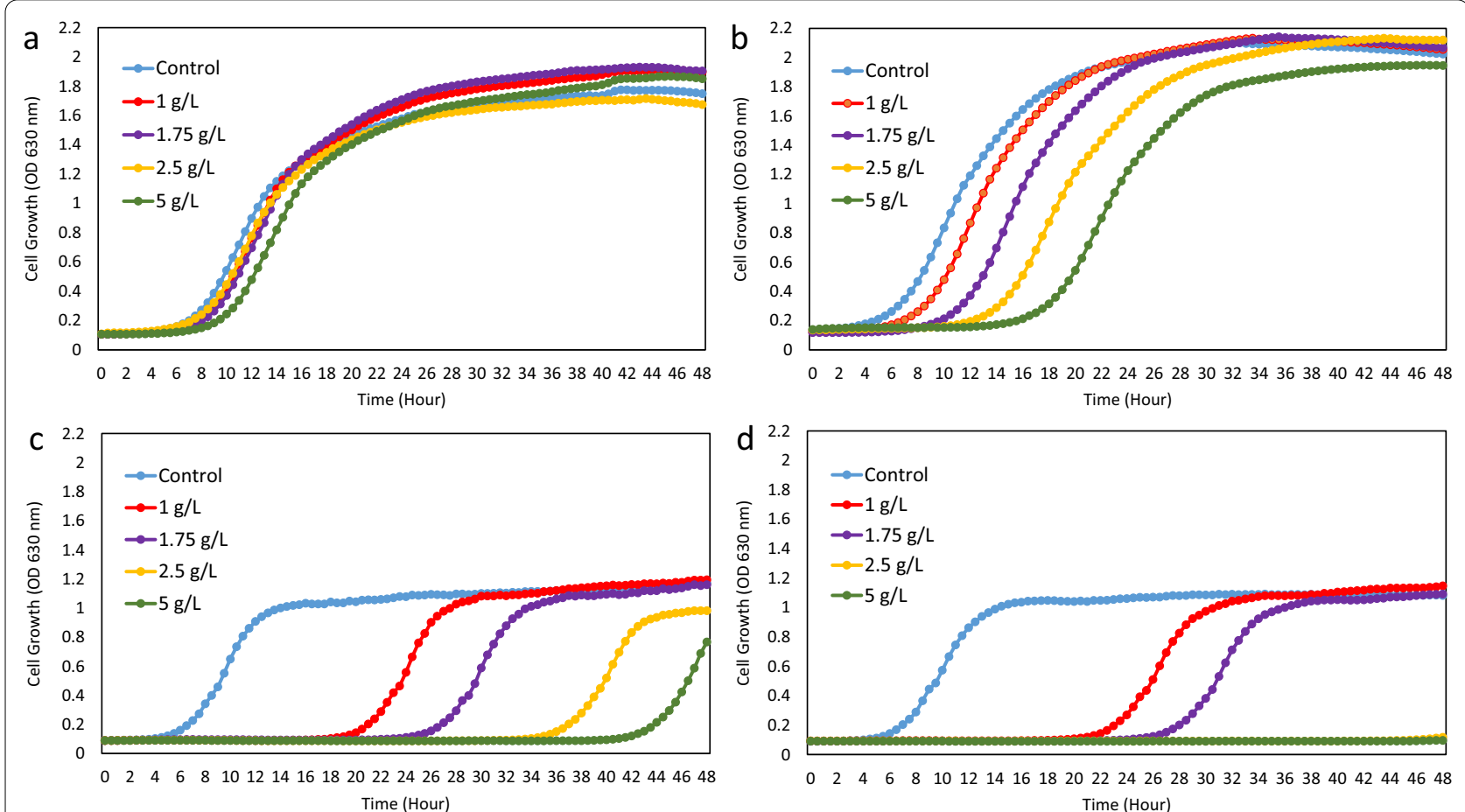

Fig. 5 Pinene resistance of $D$. radiodurans $\triangle d r 0862$ P-I-D and E. coli EcpsB strains. The growth of the strains in the rich medium containing various concentrations of a a-pinene ( $\Delta d r 0862$ PID strain), b $\beta$-pinene ( $\triangle d r 0862$ PID strain), c a-pinene (E. coli EcpsB strain), and $\mathbf{d} \beta$-pinene (E. coli EcpsB strain) was followed in microtiter plates for $48 \mathrm{~h}$. The growth curves at different pinene concentrations are shown. The experiment was done with three biological replicates

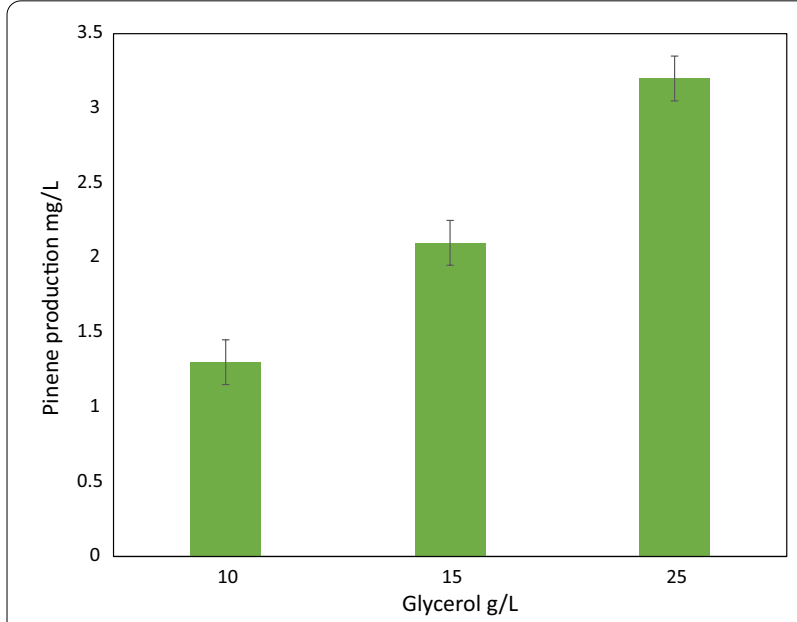

Fig. 6 Pinene production in different concentrations of glycerol in minimal glycerol medium by D. radiodurans $\triangle$ dr0862 P-I-D

production dependency on glycerol concentration in the medium (Fig. 6).

In this case, we observed that lower agitation speed and a higher percentage of dodecane $(20 \%$ instead of $10 \%)$, was necessary for optimal pinene production and extraction in the fermentation (Additional file 1: Fig. S3).
Using glycerol as the main source of carbon for fermentation has been an attractive venue for years, and the production of different molecules such as 1-propanol [7], $\gamma$-terpinene [36], limonene [37], and various enzymes [38] from glycerol using cell factories have been reported. With respect to $D$. radiodurans, this is, to the best of our knowledge, the first report describing the use of a glycerol-based minimal medium (without protein source and yeast extract), and our results show a potential for growth and production of terpene molecules from glycerol using this bacterium.

\section{Pinene production in $D$. radiodurans and $E$. coli}

In this study, we are reporting the maximal production of $3.2 \mathrm{mg} / \mathrm{l}$ of pinene in a minimal glycerol medium in shake flask cultures by $D$. radiodurans. In previous studies on pinene production, Kang et al. [29] could construct a C. glutamicum strain by the expression of GPP synthase,pinene synthase from $A$. grandis plus overexpression of $d x s$ and isopentenyl diphosphate isomerase. This engineered C. glutamicum strain could produce $0.177 \mathrm{mg} / \mathrm{L}$ pinene. In a recent report for pinene production, Xiaomin Wu et al. [39] engineered a Rhodobacter sphaeroides strain to produce pinene. Expression of a 
fusion protein of GPP synthase and pinene synthase in $R$. sphaeroides led to $0.098 \mathrm{mg} / \mathrm{L}$ pinene, and more modifications yielded a production of $0.5 \mathrm{mg} / \mathrm{L}$ in this strain. These pinene production titers indicate that $D$. radiodurans could be an appropriate host for pinene production. The titer obtained in this study, however, was lower than the highest titers obtained in a highly engineered $E$. coli strain $(166.5 \mathrm{mg} / \mathrm{L})$. This pinene production titer by E. coli strain was achieved by many manipulationsand mutagenesis (Table 3). In order to address the question of whether $D$. radiodurans is inherently a better host for pinene production than E.coli, we constructed a more basic $E$. coli production strain, comparable to the genetic makeup of our best $D$. radiodurans production strain $(\Delta d r 0862$ P-I-D), that express only the pinene synthase and the mevalonate pathway of $S$. cerevisiae. This E. coli strain was evaluated for pinene production under the same conditions as for the $D$. radiodurans strains. The E. coli strain produced $0.9 \mathrm{mg} / \mathrm{L}$ and $0.65 \mathrm{mg} / \mathrm{L}$ pinene, in the rich and the minimal glycerol medium, respectively. These amounts were 2.9 and 4.9 fold lower than the highest titer observed in $D$. radiodurans. While this is of course an artificial comparison, it does support the notion that $D$. radiodurans could represent a useful host organism for the production of monoterpenes, such as pinene (Table 2).

\section{$D$. radiodurans produces exclusively the $\beta$-pinene isomer}

When the $A$. grandis pinene synthase was expressed in $E$. coli, it led to the production of mix of pinene isomers ( $42 \% \alpha$ - and $58 \% \beta$-pinene) [16]. In contrast, when we expressed this pinene synthase in $D$. radiodurans, we observed the formation of the $\beta$-pinene exclusively (Additional file 1: Fig. S4). It has previously been reported that a fusion of pinene synthase with $E$. coli
GPP synthase allows production of the two isomers in a 50:50 ratio in E. coli [16]. Also, for this fusion protein $(\Delta d r 0862$ I:P-D), we observed exclusively $\beta$-pinene production in $D$. radiodurans. This could indicate that the intracellular conditions of $D$. radiodurans might alter the behavior of pinene synthase, resulting in the exclusive production of $\beta$-pinene.

\section{Perspectives}

In this study, we demonstrated that $D$. radiodurans can be engineered to produce pinene. The high resistance of this bacterium to toxic molecules, various sources of stress, and its ability to grow on various carbon sources could make $D$. radiodurans an appropriate candidate for the production of pinene. Such production setup would result in the production of a valuable second-generation biofuel by utilization of lignocellulosic compounds and nutritional municipal/industrial wastes. However, for this to be economically feasible, it will be necessary to further develop the $D$. radiodurans pinene production strain. Possible strategies to do this could include evaluating alternative GPP synthases or its mutants to prevent the FPP side reaction, using mutagenesis techniques, pinene transportation modifications, and fine-tuning protein levels and redox balance in the cell. Further, harboring an optimized mevalonate pathway, enhancement of upstream pathways, and the potential of optimizing growth conditions during production should be evaluated. It has been shown that the use of high cell-density cultures for carotenoid production in $D$. radiodurans could increase the production of terpene molecules significantly [21,32], and this approach can be used for pinene production as well.

Table 3 Microbial engineered strains for pinene production

\begin{tabular}{|c|c|c|c|}
\hline Host & Engineering design & Production mg/L & References \\
\hline E.coli & Heterologous mevalonate pathway expression, IspA overexpression, pinene synthase from $P$. taeda & $\begin{array}{l}5.44 \text { (Shake Flask) } \\
970 \text { (Fed-batch) }\end{array}$ & {$[15]$} \\
\hline E. coli & $\begin{array}{l}\text { GPP synthase and pinene synthase fusion protein from A.grandis expression, heterologous meva- } \\
\text { lonate pathway expression }\end{array}$ & 32 & {$[16]$} \\
\hline E. coli & $\begin{array}{l}\text { Heterologous mevalonate pathway expression, idi and GPP synthase overexpression, mutagenesis of } \\
\text { Pinene synthase from P. taeda }\end{array}$ & 140 & {$[40]$} \\
\hline E. coli & $\begin{array}{l}\text { Pinene synthase enzyme modifications, modular co-culture system engineering to modularize the } \\
\text { heterologous mevalonate pathway expression, increasing the pinene tolerance by overexpression } \\
\text { of the efflux pumps and mutagenesis by adaptive laboratory evolution after atmospheric and room } \\
\text { temperature plasma (ARTP) }\end{array}$ & 166.5 & [17] \\
\hline C. glutamicum & $\begin{array}{l}\text { Expression of GPP synthase from P. taeda and pinene synthase from A. grandis plus overexpression of } \\
d x \text { s and idi }\end{array}$ & 0.177 & {$[29]$} \\
\hline R. sphaeroides & $\begin{array}{l}\text { Expression of fusion protein of GPP synthase and pinene synthase from A.grandis ( } 0.098 \mathrm{mg} / \mathrm{L} \\
\text { pinene), and ribosomal binding site optimization, overexpressing of } d x \text { s, 1-deoxy-d-xylulose 5-phos- } \\
\text { phate reductoisomerase, and idi ( } 0.5 \mathrm{mg} / \mathrm{L} \text { pinene) }\end{array}$ & 0.5 & [39] \\
\hline
\end{tabular}




\section{Conclusions}

To the best of our knowledge, this study is the first report on monoterpene production in $D$. radiodurans using a minimal glycerol medium. By inactivating phytoene synthase and expressing the $A$. grandis pinene synthase, the E. coli GPP synthase, and overexpressing DXS, $3.2 \mathrm{mg} / \mathrm{L}$ pinene with a yield of $0.13 \mathrm{mg}$ pinene/g glycerol and productivity of $45 \mu \mathrm{g}$ pinene/h was achieved in a minimal medium in shake flask culture. In a comparable setup, the E. coli EcpsB strain produced $0.65 \mathrm{mg} / \mathrm{L}$ pinene with a yield of $0.026 \mathrm{mg}$ pinene/g glycerol. Our results demonstrate a potential of using $D$. radiodurans as a cell factory for pinene production.

\section{Supplementary Information}

The online version contains supplementary material available at https://doi. org/10.1186/s12934-021-01674-4.

Additional file 1: Table S1. List of oligos used for vector construction and real-time PCR. Figure S1. The sequence of the pinene synthaseencoding gene codon-optimized for D. radiodurans. Figure S2. Pinene degradation or consumption by D. radiodurans in 120 h. D. radiodurans was grown in a medium supplemented with $20 \mathrm{mg} / \mathrm{L}$ of pinene isomers and residual pinene was quantified by GC-FID after $120 \mathrm{~h}$. Un-inoculated pinene supplemented medium was used as the control. Figure S3. Effect of using different concentrations of dodecane (10\% and 20\%) a in the rich and $\mathbf{b}$ the minimal glycerol medium and various agitation speed $(70,100$, 180 , and $250 \mathrm{rpm}$ ) on the pinene production by D. radiodurans $\triangle d r 0862$ P-I-D. Figure S4. GC-FID chromatograms. a Alpha-pinene standard, $\mathbf{b}$ beta-pinene standard, $\mathbf{c}$ beta-pinene production by $D$. radiodurans, and $\mathbf{d}$ alpha- and beta-pinene production by E. coli. Figure S5. Pinene synthase expression in E. coli EcpsB by different concentrations of IPTG. SDS-PAGE $4 \mathrm{~h}$ after induction.

\section{Acknowledgements}

We thank Aaron John Christian Andersen, metabolomics core manager at the department of biotechnology and biomedicine (Technical University of Denmark), for his assistance in GC-MS analysis.

\section{Authors' contributions}

SHH designed and performed all experiments. SHH, CJ, IM, HM, MB analyzed the data. SHH, CJ wrote the manuscript. IM edited the manuscript. All authors read and approved the final manuscript.

\section{Funding}

This work was supported by a Grant from the Novo Nordisk Foundation (NNF10CC1016517) to IM.

\section{Availability of data and materials}

All data generated or analyzed during this study are included in this published article and its additional files.

\section{Declarations}

Ethics approval and consent to participate Not applicable.

\section{Consent for publication}

Not applicable.

\section{Competing interests}

The authors declare that the research was conducted in the absence of any commercial or financial relationships that could be construed as a potential competing interests.

\section{Author details}

${ }^{1}$ Department of Biotechnology, Faculty of Biological Science and Technology, University of Isfahan, Isfahan, Iran. ${ }^{2}$ The Novo Nordisk Foundation Center for Biosustainability, Technical University of Denmark, Lyngby, Denmark.

${ }^{3}$ Systems and Synthetic Biology Division, Department of Biology and Biological Engineering, Chalmers University of Technology, Gothenburg, Sweden.

Received: 10 June 2021 Accepted: 8 September 2021

Published online: 26 September 2021

\section{References}

1. Ho DP, Ngo HH, Guo W. A mini review on renewable sources for biofuel. Biores Technol. 2014;169:742-9.

2. Al-Maamary HM, Kazem HA, Chaichan MT. The impact of oil price fluctuations on common renewable energies in GCC countries. Renew Sustain Energy Rev. 2017;75:989-1007.

3. Ganesan R, Manigandan S, Samuel MS, Shanmuganathan R, Brindhadevi K, Chi NTL, et al. A review on prospective production of biofuel from microalgae. Biotechnol Rep. 2020;27:e00509.

4. Raheem A, Prinsen P, Vuppaladadiyam AK, Zhao M, Luque R. A review on sustainable microalgae based biofuel and bioenergy production: recent developments. J Clean Prod. 2018;181:42-59.

5. Ko Y-S, Kim JW, Lee JA, Han T, Kim GB, Park JE, et al. Tools and strategies of systems metabolic engineering for the development of microbial cell factories for chemical production. Chem Soc Rev. 2020;49(14):4615-36.

6. Tan H, Aziz AA, Aroua M. Glycerol production and its applications as a raw material: a review. Renew Sustain Energy Rev. 2013;27:118-27.

7. Choi YJ, Park JH, Kim TY, Lee SY. Metabolic engineering of Escherichia coli for the production of 1-propanol. Metab Eng. 2012;14(5):477-86.

8. Helalat SH, Bidaj S, Samani S, Moradi M. Producing alcohol and salt stress tolerant strain of Saccharomyces cerevisiae by heterologous expression of pprl gene. Enzyme Microb Technol. 2019;124:17-22.

9. Oh Y-K, Hwang K-R, Kim C, Kim JR, Lee J-S. Recent developments and key barriers to advanced biofuels: a short review. Biores Technol. 2018:257:320-33.

10. Shi S, Si T, Liu Z, Zhang H, Ang EL, Zhao H. Metabolic engineering of a synergistic pathway for $n$-butanol production in Saccharomyces cerevisiae. Sci Rep. 2016;6(1):1-10.

11. Byun J, Han J. Catalytic production of biofuels (butene oligomers) and biochemicals (tetrahydrofurfuryl alcohol) from corn stover. Biores Technol. 2016;211:360-6.

12. Bello-Zakari B. Hydroprocessing microalgae derived hydrothermal liquefaction bio-crude for middle distillate fuels production — a review. Niger J Technol. 2015;34(4):737-49.

13. Peralta-Yahya PP, Ouellet M, Chan R, Mukhopadhyay A, Keasling JD, Lee TS. Identification and microbial production of a terpene-based advanced biofuel. Nat Commun. 2011;2(1):1-8.

14. Harvey BG, Wright ME, Quintana RL. High-density renewable fuels based on the selective dimerization of pinenes. Energy Fuels. 2010;24(1):267-73.

15. Yang J, Nie $Q$, Ren $M$, Feng $H$, Jiang $X$, Zheng $Y$, et al. Metabolic engineering of Escherichia coli for the biosynthesis of alpha-pinene. Biotechnol Biofuels. 2013;6(1):1-10.

16. Sarria S, Wong B, Martín HG, Keasling JD, Peralta-Yahya P. Microbial synthesis of pinene. ACS Synth Biol. 2014;3(7):466-75.

17. Niu F-X, He X, Wu Y-Q, Liu J-Z. Enhancing production of pinene in Escherichia coli by using a combination of tolerance, evolution, and modular co-culture engineering. Front Microbiol. 2018;9:1623.

18. Makarova KS, Aravind L, Wolf YI, Tatusov RL, Minton KW, Koonin EV, et al. Genome of the extremely radiation-resistant bacterium Deinococcus radiodurans viewed from the perspective of comparative genomics. Microbiol Mol Biol Rev. 2001;65(1):44-79. 
19. Helalat SH, Moradi M, Heidari H, Rezaei F, Yarmohamadi M, Sayadi M, et al. Investigating the efficacy of UVSE protein at repairing CPD and 6-4 pp DNA damages in human cells. J Photochem Photobiol B Biol. 2020;205:111843.

20. Gerber E, Bernard R, Castang S, Chabot N, Coze F, Dreux-Zigha A, et al. Deinococcus as new chassis for industrial biotechnology: biology, physiology and tools. J Appl Microbiol. 2015;119(1):1-10.

21. Jeong S-W, Kang CK, Choi YJ. Metabolic engineering of Deinococcus radiodurans for the production of phytoene. J Microbiol Biotechnol. 2018;28(10):1691-9.

22. Slade D, Radman M. Oxidative stress resistance in Deinococcus radiodurans. Microbiol Mol Biol Rev. 2011;75(1):133-91.

23. Tian B, Hua Y. Carotenoid biosynthesis in extremophilic DeinococcusThermus bacteria. Trends Microbiol. 2010;18(11):512-20.

24. Jeong S-W, Kim J-H, Kim J-W, Kim CY, Kim SY, Choi YJ. Metabolic engineering of extremophilic bacterium Deinococcus radiodurans for the production of the novel carotenoid deinoxanthin. Microorganisms. 2021;9(1):44.

25. Ohba H, Satoh K, Yanagisawa T, Narumi I. The radiation responsive promoter of the Deinococcus radiodurans pprA gene. Gene. 2005;363:133-41.

26. Chen A, Sherman MW, Chu C, Gonzalez N, Patel T, Contreras LM. Discovery and characterization of native Deinococcus radiodurans promoters for tunable gene expression. Appl Environ Microbiol. 2019. https://doi.org/ 10.1128/AEM.01356-19.

27. Martin VJ, Pitera DJ, Withers ST, Newman JD, Keasling JD. Engineering a mevalonate pathway in Escherichia coli for production of terpenoids. Nat Biotechnol. 2003;21(7):796-802.

28. Satoh K, Tu Z, Ohba H, Narumi I. Development of versatile shuttle vectors for Deinococcus grandis. Plasmid. 2009;62(1):1-9.

29. Kang M-K, Eom J-H, Kim Y, Um Y, Woo HM. Biosynthesis of pinene from glucose using metabolically-engineered Corynebacterium glutamicum. Biotech Lett. 2014;36(10):2069-77.

30. Meima R, Rothfuss HM, Gewin L, Lidstrom ME. Promoter cloning in the radioresistant bacterium Deinococcus radiodurans. J Bacteriol. 2001;183(10):3169-75.

31. Liu C, Sun Z, Shen S, Lin L, Li T, Tian B, et al. Identification and characterization of the geranylgeranyl diphosphate synthase in D einococcus radiodurans. Lett Appl Microbiol. 2014;58(3):219-24.
32. Kang CK, Jeong S-W, Yang JE, Choi YJ. High-yield production of lycopene from corn steep liquor and glycerol using the metabolically engineered Deinococcus radiodurans R1 Strain. J Agric Food Chem. 2020;68(18):5147-53.

33. Silva ACR, Lopes PM, Azevedo MMB, Costa DCM, Alviano CS, Alviano DS. Biological activities of a-pinene and $\beta$-pinene enantiomers. Molecules. 2012;17(6):6305-16.

34. Leite AM, Lima EO, Souza EL, Diniz MFFM, Trajano VN, Medeiros IA. Inhibitory effect of beta-pinene, alpha-pinene and eugenol on the growth of potential infectious endocarditis causing Gram-positive bacteria. Revista Brasileira de Ciências Farmacêuticas. 2007;43(1):121-6.

35. Zore GB, Thakre AD, Jadhav S, Karuppayil SM. Terpenoids inhibit Candida albicans growth by affecting membrane integrity and arrest of cell cycle. Phytomedicine. 2011;18(13):1181-90.

36. Qi C, Zhao H, Li W, Li X, Xiang H, Zhang G, et al. Production of $Y$-terpinene by metabolically engineered Escherichia coli using glycerol as feedstock. RSC Adv. 2018;8(54):30851-9.

37. Willrodt C, David C, Cornelissen S, Bühler B, Julsing MK, Schmid A. Engineering the productivity of recombinant Escherichia coli for limonene formation from glycerol in minimal media. Biotechnol J. 2014;9(8):1000-12.

38. Yang F, Hanna MA, Sun R. Value-added uses for crude glycerol-a byproduct of biodiesel production. Biotechnol Biofuels. 2012;5(1):1-10.

39. Wu X, Ma G, Liu C, Qiu X-y, Min L, Kuang J, et al. Biosynthesis of pinene in purple non-sulfur photosynthetic bacteria. Microb Cell Fact. 2021;20(1):1-8.

40. Tashiro M, Kiyota H, Kawai-Noma S, Saito K, Ikeuchi M, lijima Y, et al. Bacterial production of pinene by a laboratory-evolved pinene-synthase. ACS Synth Biol. 2016;5(9):1011-20.

\section{Publisher's Note}

Springer Nature remains neutral with regard to jurisdictional claims in published maps and institutional affiliations.
Ready to submit your research? Choose BMC and benefit from:

- fast, convenient online submission

- thorough peer review by experienced researchers in your field

- rapid publication on acceptance

- support for research data, including large and complex data types

- gold Open Access which fosters wider collaboration and increased citations

- maximum visibility for your research: over 100M website views per year

At BMC, research is always in progress.

Learn more biomedcentral.com/submissions 